\title{
Managing Volunteer Programs: Educational Strategies for Adult Learners ${ }^{1}$
}

Marilyn K. Lesmeister, Shannon Washburn, and David Jones ${ }^{2}$

\section{Teaching Adult Learners}

Many educators, whether in a formal classroom setting, a non-formal workshop, or extension education setting, have struggled to find ways to make an educational presentation informative and useful for the adult learner. It can be difficult to maximize the amount of information to present while maintaining learner interest and encouraging learners to apply what is learned. While planning a good educational experience for adult learners can be a challenge, teaching and learning is most effective when appropriate strategies are used.

\section{Characteristics of Adult Learners}

There are differences between the way adults approach learning compared to the way children learn (Apps, Brookfield, Cini \& Fritz, Cross). Pedagogy refers to the science of helping children learn; andragogy is the art and science of adults learning (Knowles).

The following are characteristics of many adult learners:
- Adults have a broad base of experience that is a rich resource for learning. The opportunity for adults to share their life experiences with others can have a valuable impact on each person's ability to relate to new information. In addition, the opportunity to share one's experiences opens the learner's mind to better receive new information.

- Adults are primarily interested in learning that is relevant to their immediate needs. Adult learners want to recognize the purpose of the learning and be able to apply it soon.

- An adult makes the choice to learn. Adults prefer to be self-directed in learning rather than being dependent on someone else to be responsible for his/her learning success.

"The interest of adults in learning is heightened when they deal with problems directly concerning them and having immediate application. Further, adults have within themselves the capacity to solve their own problems," (Conti).

1. This document is FCS9241, one of a series of the Family Youth and Community Sciences Department, Florida Cooperative Extension Service, Institute of Food and Agricultural Sciences, University of Florida. Original publication date May 2006. Visit the EDIS Web Site at http://edis.ifas.ufl.edu.

2. Marilyn K. Lesmesiter, Ph.D., Department of Family, Youth and Community Science, Shannon Washburn, Ph.D, Agricultural Education and Communications, and David Jones, Agriculture Education and Communications, Florida Cooperation Extension Service, University of Florida/IFAS, Gainesville, FL 32611.

The Institute of Food and Agricultural Sciences (IFAS) is an Equal Opportunity Institution authorized to provide research, educational information and other services only to individuals and institutions that function with non-discrimination with respect to race, creed, color, religion, age, disability, sex, sexual orientation, marital status, national origin, political opinions or affiliations. U.S. Department of Agriculture, Cooperative Extension Service, University of Florida, IFAS, Florida A. \& M. University Cooperative Extension Program, and Boards of County Commissioners Cooperating. Larry Arrington, Dean 


\section{Barriers to Adult Learning}

While research shows that aging does not reduce one's ability to learn, adults may experience one or more barriers to learning. Barriers to learning can be mental or emotional, such as: having unrealistic goals; needing to unlearn outdated information; or, ineffective habits.

Other barriers to learning can be physical, such as: diminished vision or hearing; restricted mobility; or health issues that reduce concentration.

Adults are hesitant to risk "failure". They may feel uncomfortable in a situation where they may not have all the answers. Adults may avoid a learning opportunity where they perceive risk of self-esteem, reputation, or perceived success.

Adults have many demands on their time. Adults will set priorities for their time as they make choices about workshop pre-requisites and reading assignments.

When educators understand adult learners and develop educational strategies consistent with those characteristics, then adult learners can participate openly, take appropriate risk, enjoy, and apply learning.

"For most adult learners, unlearning is an essential part of the learning process. Often an adult learner must set aside old ideas, old ways of thinking and old skills. Unlearning must occur before the new learning can be attended to (and) can be a troublesome, painful process that takes time. In some ways, one can compare unlearning to the grieving process." (Apps, p. 101).

\section{Shared Characteristics}

While some learning characteristics are unique to adults, there are many similarities between the way adults and youth learn. Some enjoy listening, others learn through using their hands, and others want to discuss information. So in any group of learners, young or mature, a variety of learning strategies are helpful.
Many people have difficulty learning if they are not actively involved. Below are three educational strategies that engage learners with subject matter and one another. Think/pair/share; round robin discussion; and, role-play. These strategies can help learners discuss ideas, share life experience, test options, and learn together.

\section{Strategy: Think/Pair/Share}

The Think/Pair/Share strategy provides structure in a learning environment for individuals to consider their response alone, then share thoughts with another person before expressing thoughts in a larger group. Sharing thoughts with one peer helps adult learners become comfortable with their response before they are asked to share it with others

\section{Reasons to Use This Strategy}

The Think/Pair/Share method is effective early in the learning experience to introduce adults to other learners, build learner confidence, and to establish a positive interactive environment with open dialogue. This strategy is helpful within groups where individuals are hesitant to speak. When an adult learns that others have similar feelings, he/she may become more comfortable. It works well for sharing experiences, and to gain input through use of any open-ended question. Adult learners appreciate the opportunity to network, which is inherent in this strategy.

\section{Educator's Role}

\section{Before Workshop}

Review the educational goals of the workshop.

Determine what learning objectives could be met through use of this strategy.

Determine the open-ended question that will be posed to the group and how much time will be allotted to each portion of the activity. The question should ask learners to analyze, evaluate, or apply material to something else they know. 


\section{During the Workshop}

1. Distribute note cards and pencils to each learner.

2. Ask learners to use the note card to write their response(s) to the question(s) being asked. Announce the time limit for this part of the activity. This allows learners to formulate thoughts prior to being asked to share them with others.

3. Pose an open-ended question to the group. Clearly state the question using printed and verbal instructions.

4. Announce the amount of time available to share their responses with one other person. Before the discussion begins, announce the signal that will be used to close discussion. During this sharing period, monitor the discussion by moving through the room and listening to the pair discussions. If the majority of groups are no longer talking about the assigned topic, then signal the close of this discussion.

5. Finally, ask for volunteers from several "pairs" to share responses with the larger group. Adults may become more comfortable to share experiences with the larger group, when there has been a successful exchange in pairs.

6. Write key words and phrases on newsprint during the final discussion.

\section{After the Think/Pair/Share Discussion}

Thank members of the group for their participation and comments. This will increase their level of confidence and encourage them to participate more readily in the future.

\section{Strategy: Round-Robin Discussion}

The round-robin provides a structure for every participant to contribute to a discussion in a small (5) or large (45) group. This strategy is most successful with adult learners who know one another or with adults who are comfortable speaking in a larger group.

\section{Reasons to Use This Strategy}

The round-robin discussion prevents a participant from dominating or withdrawing from the conversation. This technique works well when there is need to find a common goal, form group consensus, or determine group action.

\section{Educator's Role}

\section{Before the Workshop}

Determine how this strategy supports the goal of the educational experience. Pre-plan one or more questions that address a learning concept. Understand the purpose for using each question. Determine the amount of time available for a round-robin discussion. The available time and the nature of the topic will help determine if this strategy is implemented with one large group or several smaller discussion groups. Gather newsprint paper, tape, and markers for each group to use.

\section{During the Workshop}

1. Determine the size of the discussion group(s). If the group is to be divided into small discussion groups, organize groups to incorporate diverse representation of people in the room. If learners already know one another, allowing them to self-select their groups may limit the diversity of opinions shared, because most people will group with others who share the same opinion. Invite the group(s) to sit in a circle, or arrangement where individuals can see one another easily. If the round-robin discussion will be conducted in several small groups, then:

2. Announce the amount of time available to complete discussion of the question(s). (If the question is simple, plan about 2 minutes per person. If the question(s) is complex, allow $5-7$ minutes per person.)

3. Ask group(s) to choose a facilitator to lead the group and to ensure respectful communication during the discussion. (If the round-robin will be conducted as one large group, then the educator leads the discussion.) 
4. Ask group(s) to select a reporter to capture key words or ideas on newsprint paper from each persons input in the group. These ideas will be shared later.

5. Communicate the round-robin structure to the entire group:

a. When a question is posed, each person around the circle (in order) will respond to it.

b. When every person has responded once, continue to go around the group, one-by-one, until no additional ideas are added to the discussion. If an individual chooses not to speak, he may respond by saying, "pass."

c. When all participants have responded, then a second question may be posed, and participants will take turns responding around the circle in the same order.

6. Now pose the question to the group. State the question(s) verbally and in print. This helps each learner participate fully, even if he did not hear part of the instructions.

7. Variations to use during the round-robin discussion:

a. All small groups could be assigned the same question or topic; or

b. Each small group may be assigned different, but related topics; or

c. Each small group may select their own topic from a broad, general question.

8. Bring a close to the small group discussion by announcing a 2-minute warning to conclude. Ask all participants to bring their attention back to the front of the room.

9. Define the expectation for round-robin reports, such as:

a. Group reporter will report all discussion ideas; or

b. Every group reporter will share thoughts that have not been stated by another groups; or c. Each group reporter will write all ideas on newsprint to post on a wall, but will report only one idea to the total group; or

d. The reporter will submit the written summary of the group discussion for future reference, but no verbal report is given.

\section{After the Round Robin Discussion}

Review several key learning concepts from the group reports. Restate the value of everyone's input, as they shared experiences in this learning community.

\section{Strategy: Role-Play}

The purpose of a role-play is to place learners in a character or role in order for them to feel or observe a specific situation. A role-play is designed to represent what can happen in a real situation. A small group of participant "actors" present a real-life situation. Each role-play character may have an exact script or just a brief description of his character to work from.

Real-life skills, attitudes, and behaviors can be portrayed. The "actors" have the opportunity to feel and reflect on a specific perspective that can occur during real-life situations. Other learners observe the role-play, then process what they saw and heard.

\section{Reasons to Use This Strategy}

The role-play method fits into training programs where participants are learning how to prepare for realistic encounters with others. It helps learners develop an appreciation for multiple perspectives, and various ways people are impacted by a situation. Implemented with a good sense of humor, this technique can also lighten the mood and provide participants valuable information in a relaxed environment.

\section{Educator's Role}

\section{Before Workshop}

1. Determine the concept(s) that could be taught using a role-play. 
2. Determine the goal of the role-play.

3. Develop a (written) situation that includes two or more characters, a description of each character, and an interaction between the characters. The character roles may be written in detail or just outlined.

\section{During the Workshop}

1. Establish the rules for observation, "These friends and neighbors are being asked to play a part. Nothing they say or do, should be interpreted as the way they would act in a real situation. They are acting. Each of them is representing an "assigned" perspective to allow us to observe what can happen in the real world."

2. Announce the goal of the role play(s), such as:

a) To observe the worst attitudes and behavior between two adult volunteers who are disagreeing about how to coordinate a parent recognition night.

b) To observe the best attitudes and behavior between two teens, who are not agreeing about how to conduct a fund-raising project, but are working through the challenges anyway.

3. Make private notes of key teaching/learning concepts that are being presented by the actors in the role-play.

\section{After the Role-Play}

Thank the "actors" for being part of the teaching/learning experience. Then, lead the discussion to process what was learned. Pose questions, such as: "What were the problems you observed in this situation? What skills were absent? What attitudes or behavior made the situation worse? What skills were used to make the relationship work? How can positive skills, attitudes and behaviors be learned? What would you do in this situation? Did you see any examples when an adult needed to "unlearn" something?"

\section{Conclusion}

Adults have life experience that makes them unique learners. Effective strategies can support and enhance adult learning. When educators understand the characteristics of adult learners and use appropriate teaching strategies, then they can help adults enjoy and apply learning. To be effective, educators should choose teaching/learning strategies that:

- include variety;

- invite adults to share their life experience;

- value varying perspectives;

- support learning, without wasting time or risking their self-confidence;

- remove or compensate for possible physical barriers to learning; and

- help learners integrate ideas into their lives as soon as possible.

\section{References}

Apps, J. W. (1988). Higher education in a learning society: Meeting new demands for education and training. San Francisco: Jossey-Bass.

Brookfield, S. D. (1987). Understanding and facilitating adult learning. San Francisco: Jossey-Bass.

Cini, M. A., \& Harden-Fritz, J. M. (1998). How adult students view leadership: Implications for leadership educators. Association of Leadership Educators, Charleston, South Carolina.

Conti, G. J. (1985). Adult Education Quarterly, 35(4), 221.

Cross, K. P. (1987). Adults as learners. San Francisco: Jossey-Bass.

Knowles, M. S. (1975). Self-directed learning. New York: Association Press. 